\title{
Identifying Learners' Difficulties in ESL Reading Comprehension
}

\author{
Yomana Chandran, Parilah M. Shah \\ Universiti Kebangsaan Malaysia, Bangi, Selangor, Malaysia \\ Email:yomana.chandran@gmail.com
}

How to cite this paper: Chandran, Y., \& Shah, P. M. (2019). Identifying Learners' Difficulties in ESL Reading Comprehension. Creative Education, 10, 3372-3384. https://doi.org/10.4236/ce.2019.1013259

Received: November 19, 2019

Accepted: December 13, 2019

Published: December 16, 2019

Copyright $\odot 2019$ by author(s) and Scientific Research Publishing Inc. This work is licensed under the Creative Commons Attribution International License (CC BY 4.0).

http://creativecommons.org/licenses/by/4.0/

\begin{abstract}
Reading is one of the fundamental skills in language learning and all English as Second Language (ESL) learners need to acquire it in order to master a language. However, statistics show that Malaysians are not reading enough especially the school students who are labeled as reluctant readers. This is deeply reflected in their reading comprehension which is one of the tested components in the SPM examination. Therefore, this study aimed to identify the learners' difficulties in ESL reading comprehension. Thus, a survey was conducted among 80 upper secondary students in Johor. Questionnaires were used in the survey and given out to the respondents involved. The data obtained from the survey were analysed using SPSS. There were five categories of reading comprehension difficulties among the upper secondary school students. Based on the analysis, it was found that most of the students have agreed that the main difficulty faced by them in ESL reading comprehension is related to the reading process. Finally, the implications of these findings on ESL reading comprehension difficulties were discussed from the aspects of what the teachers could do in their teaching practices to address this issue and provide ways to solve them.
\end{abstract}

\section{Keywords}

ESL Learners, Identify, Reading Comprehension, Difficulties, Secondary School Students

\section{Introduction}

As known to everyone, one of the most important elements and essential tools in English language learning is reading skill (Pandian, 1997; Mokatsi, 2005). Their view supports Krashen (1993), who stated that the readers are able to develop good writing style, an adequate vocabulary and advanced grammar and become 
excellent spellers through reading process. As we are all aware of, this skill indeed helps the readers to obtain the required information from the various types of reading materials, ease their thinking, acquire the necessary knowledge and amend themselves in terms of language command and vocabulary as well as it influences the development of the other language learning skills.

According to Inderjit (2014), reading skill has become a cornerstone for success in life. This is also emphasised by Merga \& Roni (2018) who have stated that reading skill is an independent skill which promotes lifelong continued literacy engagement. In other words, this skill is seen as an important tool in every professional field around the world to be able to recognise, understand and comprehend written or printed materials, which helps the readers to get engaged with the world around them. Thus, it is undeniable that reading skill is the master of all language learning skills because without it, one is considered having no intelligence and blind in knowledge.

Practically, when one talks about reading skill, there are many kinds of reading materials that can be chosen by the readers such as magazines, storybooks, journals, newspapers, poems, novels, short stories and plays. It depends on the readers in choosing the materials they want to read. Besides choosing the materials to read, according to Nuttall (1982), he has emphasised that there are four ways of reading which are known as scanning, skimming, intensive reading and extensive reading. In order to achieve the reading goals, the best way of reading needs to be chosen by the readers. Thus, this proves that the purpose and way of reading are interrelated which depend on the readers.

As widely known, reading skill is the essential skill that must be acquired during the process of language learning. New Straits Times (2012) reported that statistics shown in 2010 has proven that Malaysians read between 8 to 12 books compared with only 2 in 1995. This is supported by Muhyiddin Yassin (2013) who had stated that Malaysians are still not reading enough and they like reading light materials such as newspapers and magazines only. Although years have passed, the data obtained have concluded that there is no change in the interest of Malaysians towards reading. This implies that in general, Malaysians regardless of their age and status do not read enough and reading skill is not acquired well by them.

The main issue that has been significant is that although reading skill is regarded as the most important skill in the academic sector, it is not promoted and not successful as expected among the students. This has brought to a scenario where the school students in our country are unable to comprehend reading texts not only during the teaching and learning sessions but also in the examination as well as it is one of the compulsorily tested components in the examination. If the students fail to comprehend a text, thus their language learning will not be successful as expected as the reading skill acts as the mother of all language learning skills.

Therefore, it is found that analyses and researches have been done before on 
reading comprehension difficulties among students in other countries such as Thailand, Indonesia and Vietnam who learn English as Foreign Language (EFL). However, only a few researches have been done on students in Malaysia pertaining to reading habits and reading attitudes but not specifically on ESL reading comprehension. Each analysis has found its way out to solve the issue identified. Thus, a way is much needed to identify the issue related to reading comprehension among Malaysian students in order to solve it.

By all means, reading skill is deeply associated with our lives in terms of knowledge and new information without which, one has not lived his life to the fullest. Reading is also witnessed as a way of communication and interaction among the educated society like ours. This is stated in a research by Inderjit (2014) too. Reading is the necessary and needed skill by the students in their academic achievement. Therefore, a research was entitled to be carried out in order to identify the learners' difficulties in ESL reading comprehension. Without knowing the exact ESL reading comprehension difficulties, no one will be able to arrive at any solution. Thus, the purpose of this study was to identify the learners' difficulties in ESL reading comprehension precisely faced by the upper secondary school students at a secondary school in Johor.

\section{Literature Review}

According to Rumelhart (1977), the involvement of the text, reader and the relationship between the mentioned two aspects is called reading skill. Reading skill is also said as the skill which is used by the readers to interpret written and printed words in the reading materials to achieve their reading goals. In other words, reading is the process which connects thoughts and language as well as there is a need to be acquired by the students in order to become competent in it. Without this skill, the readers will be unable to achieve their reading competency.

One of the components of reading skill is reading comprehension. The definition of reading comprehension varies from one source to another. According to Goodman (1970), the only goal of reading skill is comprehension. Readers are required to use all syntactic information, graphic information and semantic information since they are the objectives of reading comprehension. Hence, according to Bernhardt \& James (1987), reading comprehension is giving connection to the unknown and the known information.

This is further supported by Koda (2005) who has proven that comprehension happens when the readers are able to derive and combine the obtained knowledge from their reading with their existing knowledge. In terms of reading comprehension, a reader needs both thought and perception as the readers need to use a variety of reading strategies that are mandatory to help them understand the text. So, in short, the writers usually create messages with feelings and ideas that they want to share and reading is the only way to interpret and understand the message that lies.

Reading comprehension does not only mean about translating what is written 
but it is about thinking on what the text really means. However, it is well known that it is difficult for the students to convey the idea and the meaning of the written text. To understand a text, the students must have language competence in aspects such as meaning of words, sentences, contents and importantly, the writer's ideas in the text. Thus, in simpler words, reading comprehension is the way of receiving all the needed information or the content meaning about the topic in the text. It has been identified that not all readers can understand the writer's ideas because of limited thinking ability.

Now, the old view of comprehension has been replaced by a conceptual model that has been influenced by the research on recall and memory. According to Anderson (1999), there are three different types of reading models. They are known as bottom-up, top-down and interactive models. Anderson (1999) has explained that the readers are very used to two models which are the bottom-up and top-down approaches but he has also emphasised that the best description of the model is the interactive model.

Nuttall (2005), on the other hand, has proven that the readers usually adapt to the models when they read the written texts and this is what interactive model is all about. They begin with the top-down model by which they would guess the meaning of the content and then, they would gradually move to the other model which is bottom-up to ensure that they understand the writer's intended meaning. On the other hand, Carrell, Devine and Eskey (1998) have stated that the good readers should be able to continually leap from one type of model to the other type according to what and how they read. Therefore, this model emphasises on the bottom-up model which helps the readers to recognise the words while the top-down model aids in relating with the prior knowledge to approve the assumption of meaning.

In terms of reading comprehension strategies, Oxford and Crookall (1989) have defined the mentioned strategies as various techniques which make the language learning more effective and efficient. They are also known as recognising words, using world knowledge, reading for meaning, guessing about the meaning, monitoring comprehension, identifying or inferring main ideas, distinguishing main ideas and paraphrasing. These strategies make the learning better and improve the comprehension as well as overcome the comprehension failures (Singhal, 2001). According to Nuttall (1982), he has classified the strategies into skimming, scanning, extensive reading and intensive reading.

The primary identified issue in reading skill is reading comprehension problem. There has been a list of difficulties that students face in ESL reading comprehension. According to a research conducted by Davoudi and Yousefi (2015), they had emphasised that the causes of reading comprehension difficulties for many learners include environmental, instructional, and biological sources. To keep it comprehensible, according to Gunning (2002), a prominent scholar has identified and categorised these problems as lack of reading process which means the students do not know the processes that they go through during 
reading and tackling reading comprehension, lack of vocabulary which implies that the students are not equipped with the needed list of vocabulary, lack of background knowledge as the students are not exposed to various life-related topics and do not have prior information about the topic, lack of reading purpose as they do not know the real reason of reading and lack of reading strategies as the students are not aware of the strategies related to reading skills.

There have been a few researches that had been conducted on this issue for years. The National Literacy Survey by the National Library of Malaysia has two different sets of statistical data. One in the year 1982 and the other one is in the year of 1996 by which the number of pages read by the Malaysians in the former year was only two while in the latter year, it progressed to two books. Next, the statistics from the National Statistics Department (2005) shows that Malaysians prefer pastimes such as watching videos and television as reading is not in their list of preference.

According to Kum Yoke, Mohd Anuar \& Vasuthavan (2008), they have found out in their research that Malaysians are not keen readers and Ministry of Education has to join hands with other associations to promote reading habits and practise reading culture among the people especially the students. Daily Express in 2010 has reported that even though many Malaysians have possessed literacy skills, but the habit of reading is still below the satisfactory level. This leads to a situation that the students are labelled as struggling readers which shows and proves that they have low confidence level in reading skill and do not regard themselves as avid readers even for examination purposes. This scenario does not only occur among the school students but also among the tertiary level students. This is proven by Nezami (2012) who had said that the main issue faced by teachers among the tertiary level students is insufficiency in reading comprehension which affects their academic performance.

Therefore, this implies that most students in Malaysia are able to read but they do not utilise it for the sake of their self-development. They often relate reading as restricted for their studies only and not for any other purposes. Thus, to put it in a nutshell, it has been obvious that the main difficulty in regards to ESL reading comprehension needs to be identified in order to solve the issue from engulfing the students.

\section{Methodology}

\subsection{Research Design \& Instrument}

This research was a quantitative research which enabled the researcher to quantify the obtained data and generalise results from the samples chosen for this research. This research was conducted using the survey method which allowed the researcher to derive the needed data in a specified period of time. A questionnaire was adapted and adopted from Xiubo Yi and Dan Zhang (2006) at the College of Foreign Languages, Jilin University as the research instrument. The questionnaire was set in monolingual which is in the English language. The 
questionnaire consisted Section A which was on Personal Background and Section B on Reading Comprehension Difficulties with 20 items. Each item was accompanied by 5 point Likert Scale between a range of 5 to 1 . The score of 5 represented strongly agree. The score of 4 meant agree. The score of 3 indicated that the respondent was unable to decide whether he or she agreed or disagreed with the item. The score of 2 meant disagree and the score of 1 represented strongly disagree with the item.

\subsection{Population and Sampling}

This survey was conducted in one of the 43 secondary schools in Johor. This study primarily focused on upper secondary school students. The chosen population with 100 people was aged between 16 to 17 years old who are in Form 4 and Form 5. The population was chosen based on their availability on the day of conducting the survey. Since population consisted too many individuals, there was a need to draw specified number of samples for this using a sampling technique. According to Dale (2006), there are 4 sampling techniques such as Systematic Sampling, Simple Random Sampling, Stratified Sampling and Cluster Sampling. Since a fair mixture of upper secondary school students from various classes was required, simple random sampling technique was used to draw 80 samples as respondents for this study.

\subsection{Data Collection and Data Analysis}

The survey was conducted in a supervised setting by which the researcher distributed the questionnaires to all respondents, explained on what was expected from them in the study, guided them throughout the session to ensure that the respondents answered all items in the questionnaires and complete them at ease. There was one research question in this study which was to identify the learners' difficulties in ESL reading comprehension problems faced by the upper secondary school students. All items in the questionnaire reflect the difficulties faced by the secondary school students in ESL reading comprehension.

The main goal in this research was to answer the research question by using descriptive statistics which involved the calculation on frequency of scores, percentages and mean was the medium to analyse the data obtained from the questionnaires. These statistics were chosen to observe the characteristics of the samples based on the items in the questionnaire that was used as the instrument of this research. The data obtained from the items answered by the respondents was analysed using the (SPSS) which stands for Statistical Package for Social Sciences version 21.0.

\section{Findings}

In this study, there were 57 males and 23 females who had participated as respondents. They were among 16 and 17 years old, studying in Form 4 and Form 5. Furthermore, the respondents were also chosen from all races to avoid racial 
bias. This was to reduce the limitation of the study conducted.

The first part of the questionnaire is Demographic Information. There are five items which are gender, age, year, race and reading hours. Based on Table 1 below, the missing value is obtained as 0 which reflects that no respondent has missed any of the items in Part 1. In other words, it concludes that all respondents have answered all items in Part 1 of the questionnaire without fail.

The second part of the questionnaire consists of 5 categories with 20 items which aims to find out about ESL reading comprehension difficulties among the respondents in this research. Items $1-6$ are categorised as language knowledge, items $7-10$ are about the lack of reading strategies, items $11-14$ are problems related to motivation, items $15-17$ are about background knowledge and items 18 - 20 are related to reading process. The study used a 5-point Likert scale ranging from ( 5 point) strongly agree, (4 point) agree, ( 3 point) undecided, ( 2 point) disagree and ( 1 point) strongly disagree.

The responses obtained from all the items were analysed quantitatively using descriptive statistics to determine the frequency, percentage and mean. The findings were simplified in table form with the mean and standard deviation values.

Table 2 is the individual analysis of all 20 items with their respective values of mean and standard deviation. The values of mean help the researcher to determine the most faced difficulty in the reading comprehension by the ESL learners.

Table 3 is the categorical analysis which shows the average mean values for the five categories of ESL reading comprehension difficulties faced by the respondents according to the designated items for the classified categories of ESL reading comprehension difficulties. Therefore, Table 3 above has shown a clearer picture about the reading comprehension difficulties faced by the respondents.

Based on Table 3, the mean value for each category of reading comprehension difficulties was obtained and the category with the highest mean value deduced that the upper secondary school students have the most problems related to reading process compared to the other categories. This was followed by problems related to the lack of reading strategies, their background knowledge, language knowledge and finally, the least mean value was obtained by problems related to motivation which implies that the respondent does not perceive reading motivation as the most problematic factor in reading comprehension.

On the other hand, the category with the highest mean value has three items (items 18 - 20). Each item has been represented by a table and a pie chart below for a better data representation of the respondents. These items have shown that

Table 1. Overall statistics for Section A.

\begin{tabular}{ccccccc}
\hline \multicolumn{7}{c}{ Statistics } \\
\hline & & Gender & Age & Year & Race & Reading Hours \\
\hline \multirow{2}{*}{$\mathrm{N}$} & Valid & 80 & 80 & 80 & 80 & 80 \\
& Missing & 0 & 0 & 0 & 0 & 0
\end{tabular}


Table 2. Individual analysis of items.

\begin{tabular}{ccc}
\hline Item & Mean & S.D \\
\hline Q1 & 2.6000 & 1.14295 \\
Q2 & 2.3875 & 0.98718 \\
Q3 & 2.6625 & 2.38637 \\
Q4 & 3.1500 & 1.11492 \\
Q5 & 3.6500 & 0.88732 \\
Q6 & 3.0750 & 1.00347 \\
Q7 & 37750 & 1.07885 \\
Q8 & 3.8000 & 0.91955 \\
Q9 & 3.4250 & 1.29042 \\
Q10 & 2.6750 & 1.01601 \\
Q11 & 1.7625 & 0.94459 \\
Q12 & 2.7000 & 0.90568 \\
Q13 & 3.7250 & 1.10207 \\
Q14 & 2.9625 & 1.10744 \\
Q15 & 3.5000 & 0.72914 \\
Q16 & 3.3500 & 1.06854 \\
Q17 & 2.7375 & 1.02801 \\
Q18 & 3.6625 & 1.23189 \\
Q19 & 3.8250 & 1.03850 \\
Q20 & 3.9000 & \\
\hline & & \\
\hline
\end{tabular}

Table 3. Categorical analysis of items.

\begin{tabular}{cccc}
\hline Category & Items & Mean & S.D \\
\hline Problems related to language knowledge & $1-6$ & 2.9208 & 1.2537 \\
Problems related to the lack of reading strategies & $7-10$ & 3.4188 & 1.0762 \\
Problems related to motivation & $11-14$ & 2.7875 & 1.0149 \\
Problems related to background knowledge & $15-17$ & 3.1958 & 0.9419 \\
Problems related to reading process & $18-20$ & 3.7958 & 1.1272 \\
\hline
\end{tabular}

the respondents are unanimous in answering these items as all of them have agreed to the items which are inclined towards the problems related to reading process. Thus, this has given a clear view to the researcher in answering the research question.

Item 18 projects the statement:

"I thought that I understood the passage quite well, but it turned out that I gave wrong answers to several comprehension questions after it".

Based on Table 4, item 18 has recorded the response of "strongly agree" with the highest percentage of $33.8 \%$, followed by agree with $25 \%$, undecided and disagree with $18.8 \%$ and strongly disagree with $3.8 \%$. The percentiles have been 
represented by Figure 1 in the form of pie chart.

Item 19 projects the statement:

"I cannot concentrate myself till the end of a passage. When reading a long and boring passage, I often forget the former part when I read the latter part".

Based on Table 5, item 19 has recorded the same response of strongly agree

Table 4. Analysis of Question 18.

\begin{tabular}{|c|c|c|c|c|c|}
\hline & & \multicolumn{3}{|c|}{ Q18 } & \multirow[b]{2}{*}{ Cumulative Percent } \\
\hline & & Frequency & Percent & Valid Percent & \\
\hline \multirow{6}{*}{ Valid } & Strongly Disagree & 3 & 3.8 & 3.8 & 3.8 \\
\hline & Disagree & 15 & 18.8 & 18.8 & 22.5 \\
\hline & Undecided & 15 & 18.8 & 18.8 & 41.3 \\
\hline & Agree & 20 & 25.0 & 25.0 & 66.3 \\
\hline & Strongly Agree & 27 & 33.8 & 33.8 & 100.0 \\
\hline & Total & 80 & 100.0 & 100.0 & \\
\hline
\end{tabular}

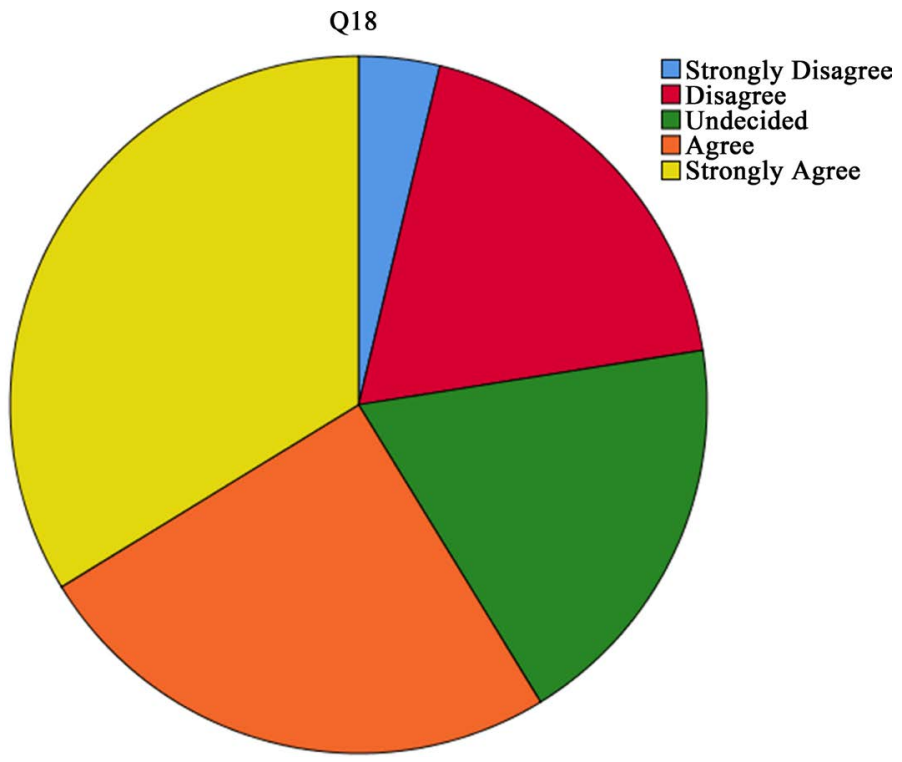

Figure 1. Graphic representation of Question 18.

Table 5. Analysis of Question 19.

\begin{tabular}{cccccc}
\hline & \multicolumn{5}{c}{ Q19 } \\
& Frequency & Percent & Valid Percent & Cumulative Percent \\
\hline \multirow{4}{*}{ Valid } & Strongly Disagree & 1 & 1.3 & 1.3 & 1.3 \\
& Disagree & 13 & 16.3 & 16.3 & 17.5 \\
& Undecided & 12 & 15.0 & 15.0 & 32.5 \\
& Agree & 27 & 33.8 & 33.8 & 66.3 \\
& Strongly Agree & 27 & 33.8 & 33.8 & 100.0 \\
\hline
\end{tabular}


and agree with the highest percentage of $33.8 \%$, followed by disagree with $16.3 \%$, undecided with $15 \%$ and strongly disagree with $1.3 \%$. This is presented in Figure 2 for a clearer representation of data.

Item 20 projects the statement:

"After reading a passage once, I seem to forget what I have already read, and have to move backward and reread it".

Based on Table 6, item 20 has recorded the response of agree with the highest percentage of $48.8 \%$, followed by strongly agree with $28.7 \%$, undecided with $10 \%$, disagree with $8.8 \%$ and strongly disagree with $3.8 \%$ as shown in Figure 3 .

\section{Discussion}

Based on the categorical average mean values obtained, the highest value is 3.7958 which showed that the respondents are inclined towards difficulties related to reading process. According to the result, the respondents do not know the proper reading process of comprehending the content of the texts based on

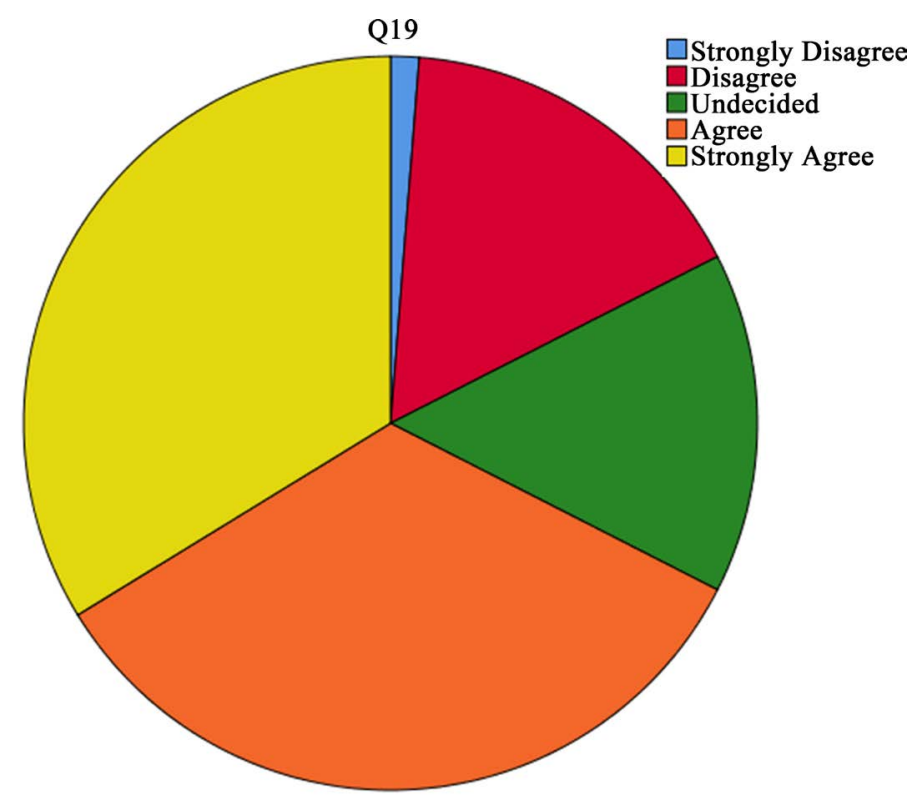

Figure 2. Graphic representation of Question 19.

Table 6. Analysis of Question 20.

\begin{tabular}{cccccc}
\hline \multicolumn{5}{c}{ Q20 } & \\
\hline & Frequency & Percent & Valid Percent & Cumulative Percent \\
\hline \multirow{4}{*}{ Valid } & Strongly Disagree & 3 & 3.8 & 3.8 & 3.8 \\
& Disagree & 7 & 8.8 & 8.8 & 12.5 \\
& Undecided & 8 & 10.0 & 10.0 & 22.5 \\
& Agree & 39 & 48.8 & 48.8 & 71.3 \\
& Strongly Agree & 23 & 28.7 & 28.7 & 100.0 \\
& Total & 80 & 100.0 & 100.0 &
\end{tabular}




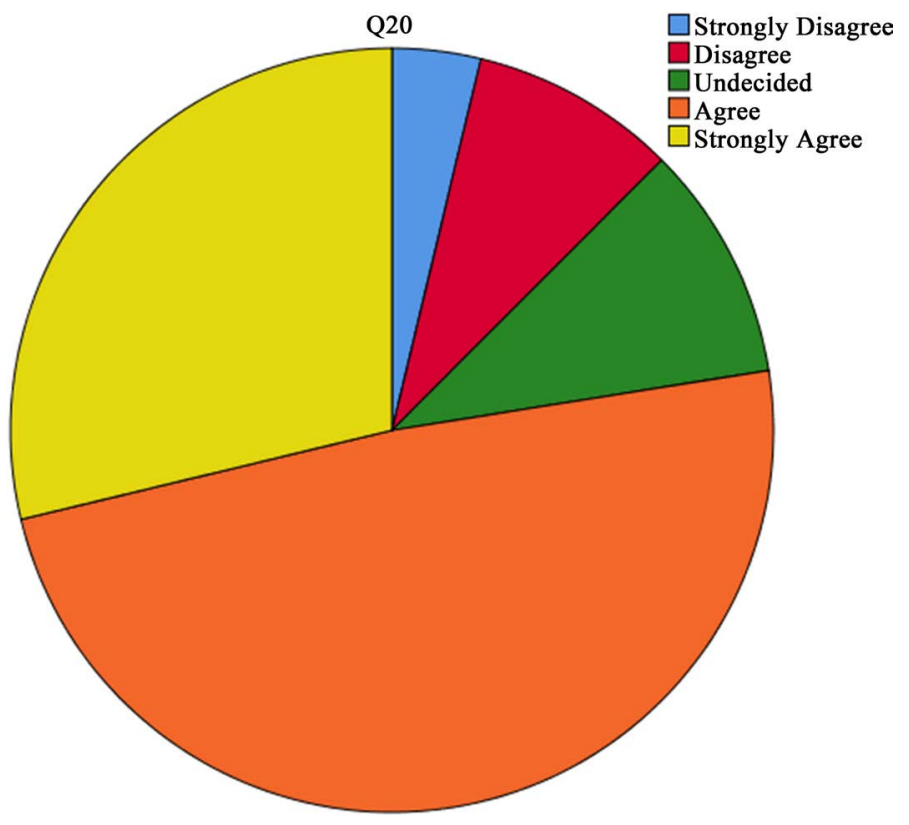

Figure 3. Graphic representation of Question 20.

the items 18 - 20 in the questionnaire. This finding also supports the research conducted by Davoudi and Yousefi (2015) who had argued that learners who face reading difficulties have comprehension problems that could be due to imprecise or ineffective word recognition and decoding methods in their reading process. When this happens, the students are unable to tackle reading comprehension. In order to solve this, the students must be exposed to the appropriate ways of reading process so that they will be able to answer the related questions based on the reading comprehension accurately.

The next difficulty is related to reading strategies which has a mean value of 3.4188. According to the result, the students have proven that they have obstacles in scanning the main idea and understanding the content of the reading comprehension based on the items 15 - 17 in the questionnaire. As mentioned by Oxford and Crookall (1989) earlier, these proposed reading strategies aid the readers in their language learning to become more effective and efficient learners without which reading comprehension goals will not be achieved. Thus, the students need to identify the proper strategies and improve them for their reading comprehension.

This, on the other hand, is followed by a mean value of 3.1958 for the difficulties related to background knowledge of the readers. According to the results obtained based on items $11-14$, students feel the reading comprehension is either boring or uninteresting, so they are unable to read it as expected and make necessary connection to their existing. This finding is aligned to what Koda (2005) has discovered in his prior research that comprehension occurs successfully when students' existing knowledge is combined and related to their newly learned knowledge from the reading comprehension. This, in other words means interest among the students to read the comprehension as designated 
helps them to achieve the reading goals. Therefore, the students will be able to make the connection between what they already know and what they should know if only if they have the interest in reading comprehension as a whole.

The other two reading comprehension difficulties are related to language knowledge and motivation which had mean values of 2.9208 and 2.7875 respectively. These two mean values are considered low which indicated that the respondents are not inclined towards ESL reading comprehension difficulties which are related to either the knowledge of language or motivation. In other words, these two categories are perceived as the least factors to cause difficulties in ESL reading comprehension. This implies that the students have the motivation for reading and the language knowledge to comprehend it.

\section{Conclusion}

To put it in a nutshell, the research objective was achieved and the research question was answered via the collection of data and findings. This has given an insight into the difficulties faced by the students in reading comprehension. Therefore, this research was seen as highly significant for many parties in this country. As mentioned by Inderjit (2014), reading skill helps to improve the academic achievement of the students and so, shared efforts are seen as necessary between the Education Ministry, policymakers, teachers, learners, society and private bodies to strategise ways and find solutions to solve the identified difficulties for the students to feel at ease in reading comprehension.

This research focused on learners' difficulties in ESL reading comprehension from one of the secondary schools only via the survey method using a questionnaire. Reading is an ongoing life-long skill, so this research could be expanded to the other secondary schools as well as higher learning institutions to identify the other reading comprehension difficulties by using other methods such as in-depth investigation or a direct assessment. This helps the researcher to avoid overgeneralisation because it involves different groups of samples as respondents.

\section{Conflicts of Interest}

The authors declare no conflicts of interest regarding the publication of this paper.

\section{References}

Anderson, N. (1999). Exploring Second Language Reading: Issues and Strategies. Boston, MA: Heinle \& Heinle.

Bernhardt, E. B., \& James, C. J. (1987). The Teaching and Testing of Comprehension in Foreign Language Learning. https://eric.ed.gov/?id=ED285420

Carrell, P. L., Devine, J., \& Eskey, D. E. (1998). Interactive Approaches to Second Language Reading. Cambridge: Cambridge University Press.

Dale, D. (2006). Population Sampling Methods for Research Studies: Definitions and Uses.

http://voices.yahoo.com/population-sampling-methods-research-studies-definitions-3 
2308.html?cat $=4$

Davoudi, M., \& Yousefi, D. (2015). Comprehension Breakdown: A Review of Research on EFL Learners' Reading Difficulty and Problems. International Journal of Language and Applied Linguistics, 1, 58-72.

Goodman, K. S. (1970). Behind the Eye: What Happens in Reading.

Gunning, T. G. (2002). Assessing and Correcting Reading and Writing Difficulties. Boston, MA: Allyn \& Bacon.

Inderjit, S. (2014). Reading Trends and Improving Reading Skills among Students in Malaysia. International Journal of Research in Social Sciences, 3, 70-81.

Koda, K. (2005). Insights into Second Language Reading: A Cross-Linguistic Approach. Cambridge: Cambridge University Press. https://doi.org/10.1017/CBO9781139524841

Krashen, S. D. (1993). The Power of Reading. Eaglewood, CO: Libraries Unlimited.

Kum Yoke, C. S., Mohd Anuar, A. A., \& Vasuthavan, E. S. (2008). A Survey of Life-Long Reading Habits among UiTM Undergraduates. Social and Management Research Journal, 4, 123-132.

Merga, M. K., \& Mat Roni, S. (2018). Children's Perceptions of the Importance and Value of Reading. Australian Journal of Education, 62, 135-153. https://doi.org/10.1177/0004944118779615

Mokatsi, R. (2005). Sharing Resources-How Library Networks Can Help Reach Education Goals. Africa: Book Aid International.

New Straits Times (2012). Malaysians Do Not Read Enough.

Nezami, S. A. (2012). A Critical Study of Comprehension Strategies and General Problems in Reading Skill Faced by Arab EFL Learners with Special Reference to Najran University in Saudi Arabia. International Journal Social Science and Education, 2, 306-316.

Nuttall, C. (1982). Teaching Reading Skill in a Foreign Language. London: Heinermann Educational Books.

Nuttall, C. (2005). Teaching Reading Skills in a Foreign Language. Oxford: Macmillan.

Oxford, R., \& Crookall, D. (1989). Research on Language Learning Strategies: Methods, Findings, and Instructional Issues. The Modern Language Journal, 73, 404-419.

Pandian, A. (1997). Reading in Malaysia. Bangi: Penerbit UKM.

Rumelhart, D. E. (1977). Toward an Interactive Model of Reading. In Theoretical Models and Processes of Reading (pp. 722-750). Newark, DE: International Reading Association. https://doi.org/10.1111/j.1540-4781.1989.tb05321.x

Singhal, M. (2001). Reading Proficiency, Reading Strategies, Metacognitive Awareness and L2 Readers. The Reading Matrix, 1.

Yassin, M. (2013). Malaysians Do Not Read Enough. http://www.malaysianbar.org.my/general_opinions/comments/malaysians_still_not_re ading_enough_says_muhyiddin.html

Yi, X., \& Zhang, D. (2006). A Psychological Analysis of English Reading Difficulty of Chinese College Learners. 